\title{
ASISTENCIA A LOS POBRES Y ENFERMOS EN EL LOGROÑO MEDIEVAL (SIGLOS XIII-XV)
}

\author{
Margarita Cantera Montenegro*
}

\begin{abstract}
RESUMEN
Margarita Cantera expone sintéticamente el panorama social en el que se desenvuelve la beneficencia medieval en Logroño, el peso de la beneficencia eclesiástica y de la que emanaba de las cofradías y gremios, principales sostenes de las asistencia a pobres y enfermos, de otra forma sólo socorridos mediante las limosnas.
\end{abstract}

\section{SUMMARY}

Margarita Cantera synthesizes the social background in which medieval beneficence in Logroño was developed, the influence of ecclesiastical beneficence and of that which came from guilds, main sources of economic help to beggars and poor ill people, who, otherwise, would have only been assisted by alms or charity.

La beneficencia medieval tenía un marcado carácter eclesiástico, de modo que la mayoría de los hospitales dependían de iglesias o monasterios. También las cofradías solían organizar la asistencia sanitaria de sus cofrades, proporcionándoles medicinas o cuidados médicos, e incluso en algunos casos en sus propios hospitales, en los que se atendería también a los pobres ${ }^{1}$. Sin embargo, los pocos datos sobre las cofradías medievales de esta ciudad ${ }^{2}$ hacen referencia sólo a

* Centro de Estudios Históricos (C.S.I.C.)

1. José SANCHEZ HERRERO, Cofradias, hospitales y beneficencia en algunas diócesis del valle del Duero, siglos $X I V$ y $X V$, «Hispania», XXXIV (1974), pág. 26. También se ocupa con detalle de los sistemas de previsión en las cofradías medievales Antonio RUMEU DE ARMAS, Historia de la previsión social en España. Cofradías, gremios, hermandades, montepios (Madrid, Pegaso, 1944), Barcelona, El Albir, 1981, págs. 127-136. Este tema de la asistencia a los pobres ha sido abordado recientemente por Carmen LOPEZ ALONSO, La pobreza en la España medieval, Madrid, 1986, págs. 369-527, dedicando especial atención a la asistencia hospitalaria en las págs. 407-474. También tratan de este problema los libros siguientes: $A$ pobreza e a assistencia a os pobres na Peninsula Iberica durante a Idade Media, Actas de las I Jornadas Luso-Españolas de Historia Medieval, Lisboa, 1973, 2 vols.; Michel MOLLAT, Les pauvres au Moyen Age. Etude sociale, París, 1978; y Manuel RIU RIU (dir.), La pobreza y la asistencia a los pobres en la Cataluña medieval, Barcelona, 1980-1982.

2. Han sido estudiados en mi artículo Las cofradias religiosas en el Logroño medieval, «Hispania Sacra», en prensa. 
la asistencia por medio de oraciones y no a la ayuda a los enfermos, aunque es indudable que ésta existía.

\section{Hospitales}

Al abordar este tema hay que tener en cuenta que en el caso de Logroño al número de enfermos y pobres que hubiese en la ciudad habría que añadir el importante contingente de peregrinos que, camino de Santiago de Compostela, necesitasen atención. A pesar de ello, no hay noticias en la documentación logroñesa sobre alberguerías y hospitales destinados exclusivamente a los peregrinos, como sí hay de otras localidades riojanas (Nájera y Santo Domingo de la Calzada, por ejemplo); quizás aquellas personas que, de paso por la ciudad, requiriesen atención médica la recibirían en alguno de los hospitales existentes sin carácter exclusivo de peregrinaje ${ }^{3}$.

Se puede establecer una diferencia entre los hospitales en general y los destinados a atender a personas que padeciesen una enfermedad concreta, como la lepra.

\section{Casas de San Lázaro}

Dado el carácter contagioso de la enfermedad y el temor que había hacia ella, los lazaretos o "casas de San Lázaro» se encontraban fuera de las ciudades, aunque situadas en las rutas de mayor tránsito; solían enclavarse en las bifurcaciones de los camininos principales a la salida de las grandes ciudades ${ }^{4}$. En el caso de Logroño podemos aventurar que el lazareto estaría al suroeste de la ciudad, en un paraje situado fuera del casco urbano incluso en la actualidad conocido como San Lázaro y que en un documento se localizaba «açerca de la dicha çibdad (de Logroño)»5.

La existencia de un hospital de San Lázaro está documentada en el año 1230 cuando el clérigo Sebastián donó en su testamento, para la comida de los enfermos, dos sueldos a éste y a otros hospitales de la ciudad'.

Pero desde estos primeros momentos del siglo XIII no vuelve a haber noticias de este lazareto hasta finales del $\mathrm{XV}$, momento en que surge una disputa sobre la provisión de dicha casa y con motivo de la cual se da algún dato sobre su régimen.

Así, en marzo de 1489, el concejo de Logroño afirmaba que «de tiempo inmemorial a esta parte» dicha casa había sido administrada por la ciudad «como patrones e administradores», siendo de patronato real ${ }^{7}$, de modo que era a los Reyes a quienes correspondía su provisión, administración y visitación. Se habla también de la escasez de recursos, que apenas eran de

3. Sobre la atención sanitaria a peregrinos es importante el clásico trabajo de Luis VAZQUEZ DE PARGA, José M. ${ }^{a}$ LACARRA y Juan URIA, Las peregrinaciones a Santiago de Compostela, Madrid, 1948-1949, 3 vols.; más breve es el artículo de Luis Del CAMPO, La medicina en el Camino de Santiago, «Príncipe de Viana», XXVII (1966), págs. 169-180.

4. Pedro LAIN ENTRALGO, Historia universal de la Medicina: III. La Edad Media, Barcelona, Salvat, 1972, pág. 289. También se ocupa de las leproserías y hospitales en general Nilda GUGLIELMI, Modos de marginalidad en la Edad Media: extranjería, pobreza, enfermedad (a propósito de estatutos de hospitales y leproserias), «Anales de Historia Antigua y Medieval», 16 (Buenos Aires, 1971), págs. 7-187), Marginalidad en la Edad Media, Buenos Aires, Eudeba, 1986, págs. 9-135.

5. Archivo General de Simancas (en adelante AGS), Registro General del Sello (en adelante $R G S$ ), fol. 401 (12-III-1489).

6. Eliseo SAINZ RIPA, Colección diplomática de las colegiatas de Albelda y Logroño, I, Logroño, 1981, doc. 26.

7. AGS, RGS, fol. 401. 
1.000 ó 1.500 maravedíes, a los que se añadían las limosnas de los vecinos, que constituían su principal fuente de ingresos.

El problema de la posesión de esta casa de San Lázaro surgió en 1486. Nicolás de Puentedura, vecino de Burgos, había sido proveído para su dirección por el vicario de la Orden, contando, además, con una carta de los Reyes en la que se ordenaba al concejo le entregase la posesión y lo tuviese bajo su amparo; y así fue durante cierto tiempo que aquél aprovechó para arreglar y retejar el edificio. Pero en marzo de 1486 Diego de Montoya, como voz mayor del concejo y cumpliendo las órdenes de éste, ocupó por la fuerza dicha casa, despojando de ella al citado Nicolás; a pesar de las cartas de excomunión y entredicho dadas por el provisor de la Orden no consiguieron su restitución, lo que movió a Nicolás de Puentedura a acudir a los Reyes, los cuales ordenaron, el 21 de agosto de 1487, se restituyese a dich a persona el citado hospital ${ }^{8}$.

Dos años más tarde el problema seguía pendiente y no era sólo Nicolás de Puentedura quien reclamaba esta casa de San Lázaro. Efectivamente, ante la súplica del concejo, los monarcas otorgaron a éste, en marzo de 1489, la administración del hospital, pues afirmaba, como ya he señalado, que la ciudad debía actuar como patrón y administrador, correspondiendo la provisión a los Reyes por ser de su patronato todas las casas de San Lázaro del reino?.

Sin embargo, los Reyes Católicos, en junio de ese año, tuvieron que reiterar la orden de que nadie ocupase la administración del centro, pues debían de decidir ellos en este asunto ${ }^{10}$. En efecto, había dos personas que reclamaban la posesión: por un lado Nicolás de Torres, vecino de Logroño, que estaba en dicha casa desde que, según afirmaba, le había sido entregada por los regidores de la ciudad un año antes. Y, por otro, Juan de Estrada, que alegaba en su favor el tener ciertas bulas y haber sido proveído por jueces eclesiásticos; ante esta reclamación la reina Isabel declaró que no correspondía a los jueces eclesiásticos entender en este asunto, sino al Consejo real, por lo que ordenaba no reclamase la disputada posesión ${ }^{11}$.

Por fin los monarcas determinaron en este asunto ordenando al concejo de Logroño que restituyese a Nicolás de Puentedura en la posesión de las casas debiendo entregarle, además, los frutos y rentas de que se había privado al hospital durante el tiempo de la disputa; el mismo día se dirigieron al corregidor de la ciudad para que ayudase al repuesto Nicolás de Puentedura ${ }^{12}$.

\section{Otros hospitales}

Más escasas son las noticias que hay sobre otros centros de atención a enfermos y pobres, y prácticamente se reducen a algunas mandas contenidas en testamentos.

Así, junto al de San Lázaro, podemos añadir otros cuatro: Rocamador, San Juan, San Gil y San Blas, De dos de ellos, San Juan «ultra Ebro», es decir, fuera de la ciudad, al norte del Ebro, y San Gil sólo tenemos noticia del año 1230, cuando el clérigo Sebastián donó en su testamento dos sueldos a cada uno de ellos para la refección de los enfermos ${ }^{13}$.

El hospital de Rocamador, o Santa María de Rocamador, es citado por primera vez en el anterior testamento del clérigo Sebastián, recibiendo la misma cantidad que los otros centros. En 1380 y 1423 vuelve a hablarse de este hospital al ser alguna propiedad suya límite de

8. AGS, RGS, fol. 209.

9. AGS, $R G S$, fol. 401.

10. AGS, $R G S$, fol. 251 (5-VI-1489).

11. AGS, $R G S$, fol. 232 (5-VI-1489).

12. AGS, $R G S$, fols. 219 y 218 .

13. E. SAINZ RIPA, Colección, I, doc. 26. 
heredades del cabildo de Santa María la Redonda objetos de algún trato ${ }^{14}$. Por último, en 1466, Pedro Martínez de Andújar disponía en su testamento la entrega de dinero para una pobre, llamada Juana, «que bive en el ospital de Rocamador»15; esta frase, por otra parte, indica cómo algunas personas faltas de recursos debían de tomar estos hospitales como lugares habituales de residencia.

Seguramente este hospital, al menos en el siglo $\mathrm{XV}$, unificó otros más pequeños existentes en la ciudad y que no podrían mantenerse por la pobreza de recursos y la escasez de personas para atenderlos ${ }^{16}$.

Del hospital de San Blas sabemos ya en el siglo XIV a través de la documentación conservada en la catedral de Santa María la Redonda; dos de las citas sólo nos muestran que alguna de sus propiedades limitaba con otras que, por una u otra razón, interesaban al cabildo, como ocurre en 1376 y $1388^{17}$. Otra, también de 1376, da información respecto a su localización, ya que es límite de unas casas situadas en la calle de «entrambas las Carnesçerías»18.

El último de los documentos, de 1488, nos habla de las propiedades que, tanto agrícolas como urbanas, poseían las «dichas iglesias e obra e ospital» de las iglesias de San Salvador y San Blas, dos parroquias gemelas acogidas en un solo edificio ${ }^{19}$. Es interesante ver cómo este hospital, seguramente al igual que los otros, estaba vinculado a una iglesia.

Sí es evidente en todos los casos el marcado carácter religioso, que se manifiesta en primer lugar, en el nombre bajo el que se acogían y que señalaría, probablemente, como queda demostrado en el caso de San Blas, su dependencia de una iglesia o «ermita»; o, también, que junto al centro de atención el pobre y enfermo estaba una iglesia para su atención espiritual y que se refleja en un documento de los antes citados respecto al hospital para leprosos, en que se habla de la casa y monasterio de San Lázaro.

No podemos olvidar, sin embargo, que muchas de estas fundaciones benéficas serían pequeños centros, con pocas camas, y que surgirían por la iniciativa de un particular; ello explica también la falta de documentación y su rápida extinción, ya sea desapareciendo ya integrándose en otro hospital mayor.

Este hecho se observa aún a fines del siglo XV; así, el 8 de marzo de 1489, los Reyes Católicos encargaron al corregidor de Logroño que se informase sobre una petición presentada por Juan Martínez de Marquina, vecino de la ciudad ${ }^{20}$ : éste, en nombre del obispo de Calahorra (lo que por otra parte muestra una vinculación eclesiástica) había empezado a hacer un hospital al otro lado del Ebro, cerca de una ermita conocida como Santa María de Munilla de Cantabria, «donde se acogiesen los romeros e otras personas que quedasen fuera de noche»; pero uno de los diputados de la ciudad, Pedro de Enciso, por enemistad personal hacia Juan

14. IDEM, Ibidem, I, doc. 232 y II, doc. 276 .

15. IDEM, Ibidem, II, doc. 328.

16. Felipe Abad León (Radiografia histórica de Logroño a la luz del Catastro del Marqués de la Ensenada, Logroño, 1978, pág. 203) dice que este hospital estaba, y está, junto al convento de San Francisco y la Plaza del Coso. Sobre la desaparición de muchos de los hospitales pequeños a lo largo del siglo XVI trata José SANCHEZ HERRERO, op. cit., pág. 31 y Carmen LOPEZ ALONSO, op. cit., págs. 449-450, quien habla del nacimiento de gran número de hospitales, coincidiendo con el auge urbano a cofradías, mientras que el movimiento integrador de esta multiplicidad hospitalaria del siglo XV se debía a un deseo de efica cia y rentabilidad.

17. E. SAINZ RIPA, Colección, I, docs. 227 y 244.

18. IDEM, Ibidem, I, doc. 226.

19. IDEM, Ibidem, I, doc. 301. Ambas parroquias fueron conocidas durante mucho tiempo, en la Edad Media, como San Salvador el Viejo y el Nuevo, hasta que la primera de ellas tomó el nombre de San Blas.

20. AGS, RGS, fol. 85 . 
Martínez quería impedir que se terminase de edificar el hospital, lo que según el promotor de la idea perjudicaría a los Reyes y «los pobres resçibirían detrimento».

\section{Limosnas}

Otra forma de asistencia a los pobres era la limosna. Y a la limosna que éstos recaudarían pidiendo por las calles y a la puerta de las iglesias vendría a sumarse la otorgada en los testamentos como una manda piadosa, ya fuese en forma de vestido ya de comida. Voy a señalar a continuación estas mandas piadosas que hacen referencia a los pobres, a veces pertenecientes a la familia del testador.

En agosto de 1230 el clérigo de Santa María la Redonda, Sebastián, disponía la entrega de 100 «canas de cordat» para vestido de los pobres, poniendo por delante a sus parientes si éstos lo necesitasen; también otorgaba 25 sueldos a un carpintero, Juan, que estaba enfermo, para que se curase ${ }^{21}$.

También clérigo de la Redonda era Tomás que, en mayo de 1309, establecía que si alguna vez los clérigos de la ciudad de Logroño no querían 34 maravedíes que dejaba para una refección anual, se repartiesen entre vecinos pobres de la localidad ${ }^{22}$.

Ferrand García de Torres, hacia 1340, había establecido la entrega de 100 maravedíes para que se vistiese a 20 pobres parientes suyos, la mitad de sayal y la otra mitad de estopa, según llegase el dinero ${ }^{23}$.

En 1347 Martín Ortiz de Agoncillo ordenaba se diese de comer pan, vino y carne o pescado, según qué día fuese a 30 pobres «envergonzados», cuyos nombres había dicho a su capellán y a su mujer; a estos mismos había confiado los pobres vecinos de Logroño a quienes quería que se repartiesen 100 varas de sayal ${ }^{24}$.

Garci Martínez, en 1373, establecía que el día de su entierro diesen de comer a 30 pobres pan, vino y carne o pescado, a quienes además debían vestir de sayal, capas o sayas. También ordenaba se diese de comer, seguramente otro día, a 5 pobres los mismos alimentos, como muestra de reverencia hacia las cinco llagas de Nuestro Señor ${ }^{25}$.

Hacia 1399 Sancha López pedía que el día de su entierro se diese de comer a 14 pobres ${ }^{26}$.

Juan Pérez de Clavijo, en mayo de 1407, disponía que se visitiera a 20 pobres, a 10 de sayal y a los otros 10 de estopa; que el día del entierro, y si ese día no se encontrasen otro día de su novena, se diera de comer a 20 pobres pan, vino y carne o pescado y, por otra parte, a otros 3 pan, vino y carne ${ }^{27}$.

Siete años más tarde, en octubre de 1414, María Díaz pedía que el día de su muerte se diese de comer a 4 pobres los alimentos ya repetidos (pan, vino y carne o pescado), mientras que Leonor, en 1420, quería se diese a $10^{28}$.

21. E. SAINZ RIPA, Colección, I, doc. 26.

22. IDEM, Ibidem, I, doc. 141 .

23. IDEM, Ibidem, I, doc. 152.

24. IDEM, Ibidem, I, doc. 166.

25. IDEM, Ibidem, I, doc. 221.

26. IDEM, Ibidem, II, doc. 255.

27. IDEM, Ibidem, II, doc. 262.

28. IDEM, Ibidem, II, docs. 267 y 273. 
Pedro Martínez de Andújar, en 1466, establecía, por un lado, que el día de su entierro se diese de comer a 10 pobres para que rogasen por su alma; y, por otra, que una vez cumplidas todas las mandas del testamento lo que sobrase se vendiese para vestir a 30 pobres de Logroño de paño «de burel o de blanco», 4 varas a cada uno, señalando los nombres de estos pobres y, en algunos casos, su situación o condición: Gonzalo «que está tollido, en la Puerta Nueva»; Juana, «que bive en el ospital de Rocamador»; a «un pobre que anda con los palos acorcovado»; Martín Juan, ciego; y otros nombres ${ }^{29}$.

Sancha Pérez en 1470 y Fernando Martínez de Tricio en 1477 establecían que el día de su entierro se diera de comer a 12 pobres pan, vino y carne o pescado ${ }^{30}$.

En 1499 el doctor Pedro Jiménez de Enciso, arcediano de Logroño, ordenaba que se distribuyera una pieza de paño entre los pobres de Enciso y otra entre los de Logroño ${ }^{31}$.

Estos son los escasos datos que conocemos sobre el cuidado prestado a los pobres y enfermos en el Logroño de los siglos XIII al XV. Se observa a través de ellos el papel primordial de la Iglesia y la consideración del pobre y del enfermo como «otro Cristo» al que había que socorrer por caridad; pero es más que probable que esta ayuda fuese insuficiente y no llegase a todos los necesitados.

29. IDEM, Ibidem, II, doc. 328. En una relación de los gastos hechos en el cumplimiento de este testamento (doc. 329), redactada sólo siete días después de aquél ( 8 de noviembre de 1466), se hace referencia a diversos gastos por la confección de los vestidos para los pobres.

30. IDEM, Ibidem, II, docs. 334 y 339.

31. IDEM, Ibidem, II, doc. 376. 